\title{
XÁC ĐỊNH VỊ THẾ CẠNH TRANH CỦA MỘT SỐ NHÀ HÀNG TIỆC CƯớI TẠI THÀNH PHỐ HỒ CHÍ MINH
}

\author{
NGUYỄN NGUYÊN PHƯƠNG \\ Khoa Quản trị Kinh doanh - Truòng Đại học Công nghiệp Thành phố Hồ Chí Minh \\ nguyennguyenphuong@iuh.edu.vn
}

Tóm tắt. Nghiên cứu được thực hiện nhằm xác định vị thế cạnh tranh của một số nhà hàng tiệc cưới trên địa bàn Tp.HCM. Vận dụng các học thuyết và mô hình có liên quan, cũng như qua thảo luận với chuyên gia, tác giả đề xuất mô hình nghiên cứu gồm 05 nhân tố. Sau quá trình thu thập và xử lý dữ liệu bằng phần mềm SPSS, excel và kết hợp với việc sử dụng ma trận hình ảnh cạnh tranh, kết quả nghiên cứu đo lường được năng lực cạnh tranh bên trong của 03 doanh nghiệp được đề cập dựa trên 05 yếu tố: nhân viên phục vụ, thương hiệu, năng lực quản lý, sản phẩm, cơ sở vật chất. Vị thế cạnh tranh từ cao đến thấp là: Metropole, Capella Parkview và Phú Nhuận plaza. Từ đó, với vai trò quản lý của Phú Nhuận Plaza tác giả đề xuất một số hàm ý quản trị để doanh nghiệp có khả năng cạnh tranh tốt hơn trên thị trường.

Từ khóa: cạnh tranh, trung tâm tiệc cưới, xác định vị thế cạnh tranh

\section{DEFINING COMPETITIVE POSITION OF SOME WEDDING CENTERS IN HOCHIMINH CITY}

\begin{abstract}
The study was conducted to identify competitive position of some wedding centers in Ho Chi Minh city. By applying some theorical models related to competitive position, discussing with experts, five factors affecting to competitive position of wedding centers are selected. After collecting and analyzing the data by using SPSS software, excel and applying the method of Competitive Profile Matrix, the findings show the competitive capacity the competitive positions of three wedding centers based on 05 factor: staff, brand, management capacity, products, infrastructure. The competitive positions of three wedding centers are also pinpointed. The first competitivve position belongs to Metropole, following by Capella Parkview and Phu Nhuan Plaza. As perspective of Phu Nhuan plaza, some implications are suggested to boost its competitive advantages to becom better in marketplace.
\end{abstract}

Keywords. competitiveness, wedding center, positioning competitiveness

\section{VẤN ĐỀ NGHIÊN CỨU}

So với nhiều lĩnh vực khác, ngành kinh doanh trung tâm hội nghị - tiệc cưới đang mang lại doanh thu khá lớn. Tuy nhiên, trong tình hình kinh doanh thực tế, cuộc đua giành thị phần trong lĩnh vực kinh doanh nhà hàng tiệc cưới ở tất cả các phân khúc đang diễn ra quyết liệt tạo ra sức ép cạnh tranh gay gắt. Trước thực trạng đó, việc xác định những nhân tố tác động đến năng lực cạnh tranh bên trong, đo lường năng lực cạnh tranh của doanh nghiệp, để biết được vị thế cạnh tranh hiện tại, giúp doanh nghiệp tìm ra giải pháp tập trung nguồn lực phát triên hơn là điều hết sức cần thiết.

Tại khu vực trung tâm thành phố, đặc biệt là khu vực quận Phú Nhuận và Quận 3, qua khảo sát sơ bộ đối với khách hàng, 03 nhà hàng tiệc cưới được khách hàng nhớ và nhắc đến nhiều nhất là Phú Nhuận plaza, Capella Parkview và Metrople. Các trung tâm tiệc cưới này cũng không nằm ngoài cuộc cạnh tranh và đang ngày càng chú trọng hoàn thiện, phát triển những thế mạnh đặc trưng của mình để có được vị thế vững chắc trong môi trường kinh doanh hiện nay.

Đề tài nhằm xác định vị thế cạnh tranh của một số nhà hàng tiệc cưới trên địa bàn Tp.HCM. Trong đó có các mục tiêu cụ thể như sau: Xây dựng mô hình các yếu tố ảnh hưởng đến năng lực cạnh tranh bên trong của các nhà hàng tiệc cưới; Xác định mức độ quan trọng của từng yếu tố; Đo lường năng lực cạnh tranh bên trong của 03 nhà hàng tiệc cưới được chọn thông qua khảo sát sơ bộ và từ đó so sánh vị thế cạnh tranh của các doanh nghiệp được khảo sát; Với vai trò là quản lý của Nhà hàng Tiệc cưới Phú Nhuận plaza, tác giả đề xuất một số hàm ý quản trị nhằm nâng cao vị thế cạnh tranh cho nhà hàng tiệc cưới này. 
Đối tượng nghiên cứu của đề tài là tìm hiểu năng lực cạnh tranh bên trong của một số nhà hàng tiệc cưới trên địa bàn Tp.HCM. Khách thể nghiên cứu là những khách hàng của 03 nhà hàng tiệc cưới qua phỏng vấn đã được chọn.

Nghiên cứu được tiến hành trong phạm vi quận Phú Nhuận và Quận 3, từ tháng 12/2015 đến tháng 6/2016. Nội dung cốt lõi là xác định vị thế cạnh tranh và so sánh năng lực cạnh tranh bên trong của 03 nhà hàng tiệc cưới Phú Nhuận plaza, Capella Parkview và Metrople.

\section{CƠ SỞ LÝ THUYẾT VÀ MÔ HİNH NGHIÊN CÚU}

\subsection{Cơ sở lý thuyết}

Cạnh tranh là một trong những đặc trưng cơ bản của nền kinh tế thị trường, là năng lực phát triển của kinh tế thị trường. Đây là một hiện tượng kinh tế xã hội phức tạp nên có nhiều quan niệm khác nhau về cạnh tranh. Trong nghiên cứu này, cạnh tranh được hiểu là một hoạt động kinh tế nhằm tiến đến mục tiêu riêng của các chủ thể kinh tế, họ ganh đua nhau tìm mọi biện pháp để đạt mục đích của mình, chiếm lĩnh thị trường, giành lấy thị phần và điều kiện sản xuất,... có lợi nhất cũng như tối đa hóa lợi nhuận.

Sanchez \& Heene (2004) cho rằng năng lực cạnh tranh của doanh nghiệp là khả năng kết hợp các nguồn lực của doanh nghiệp nhằm tạo ra lợi thế cạnh tranh cho doanh nghiệp. Do đó, lợi thế cạnh tranh là sở hữu của những giá trị đặc thù, có thể sử dụng được để "nắm bắt cơ hội", và kinh doanh có lãi. Khi nói đến lợi thế cạnh tranh, là nói đến lợi thế mà một doanh nghiệp, một quốc gia đang có và có thể có, so với các đối thủ cạnh tranh của họ. Lợi thế cạnh tranh là một khái niệm vừa có tính vi mô (cho doanh nghiệp), vừa có tính vĩ mô (ở cấp quốc gia).

Mỗi doanh nghiệp tham gia vào thị trường có một vị thế nhất định so với các đối thủ cạnh tranh. Vì vậy, vị thế cạnh tranh là biểu thị sức mạnh cạnh tranh của doanh nghiệp trên thị trường. Viẹ̣c xác định vị thế cạnh tranh là quá trình doanh nghiệp chỉ ra sự khác biệt và tạo ra giá trị của sản phẩm hoặc dịch vụ mà doanh nghiệp đang cung cấp đối với những đối thủ cạnh tranh khác trên thị trường. Đó là khả năng tạo ra điểm riêng của mình trong bức tranh cạnh tranh, là chiến thắng trong tâm trí khách hàng, được biết đến vì một điều nhất định nào đó.

Về dịch vụ tiệc cưới, đây được hiểu là các hoạt động dịch vụ cụ thể nhằm đáp ứng nhu cầu khách hàng đến dự lễ cưới tại nhà hàng. Nơi tổ chức tiệc cưới gần như là yếu tố quan trọng nhất bởi đây là yếu tố quyết định ngày vui có diễn ra tốt đẹp hay không. Vì thế, các khách hàng luôn chọn lựa nơi có dịch vụ cưới tốt, đội ngũ phục vụ chuyên nghiệp, món ăn đãi tiệc ngon miệng, trang trí sảnh tiệc cưới đẹp và quan trọng là có mức giá phù hợp với ngân sách cho ngày cưới.

Có rất nhiều học thuyết và mô hình nghiên cứu trên thế giới đã và đang nghiên cứu về vấn đề năng lực cạnh tranh bên trong của các doanh nghiệp. Đầu tiên có thể nói đến đó là Mô hình viên kim cương là mô hình kinh tế được phát triển bởi Michael Porter (1985) trong cuốn sách Lợi thế cạnh tranh của các quốc gia. Porter đã xây dựng lý thuyết về bốn thuộc tính lớn của một quốc gia hình thành nên môi trường cạnh tranh cho các công ty tại nước đó. Những thuộc tính này thúc đẩy hoặc ngăn cản tạo ra lợi thế cạnh tranh của quốc gia, đó là: Điều kiện các yếu tố sản xuất, các điều kiện về cầu, các ngành công nghiệp hỗ trợ và liên quan, chiến lược, cấu trúc công ty và đối thủ cạnh tranh. Trong đó, ông lập luận rằng các công ty có khả năng thành công cao nhất tại ngành hoặc phân ngành trong đó mô hình kim cương đạt thuận lợi nhất. Ông cũng cho rằng mô hình kim cương là một hệ thống tương tác và củng cố lẫn nhau. Tác động của một thuộc tính sẽ phụ thuộc vào tình trạng của thuộc tính khác.

Lý thuyết cạnh tranh VRIN - Barney (1991) là cơ sở để xác định được nguồn lực có phải là nguồn lợi thế cạnh tranh bền vững. Để làm cơ sở cho lợi thế cạnh tranh bền vững, nguồn lực phải đáp ứng được các yếu tố sau: tính giá trị, tính hiếm có, tính không thể bắt chước và tính không thể thay thế. Các tiêu chí của mô hình VRIN làm rõ những qui tắc đưa ra thực tiễn tốt nhất cho những nguồn lợi thế cạnh tranh. Nếu đối thủ cạnh tranh có thể dễ dàng hiểu và sao chép năng lực của doanh nghiệp thì đó không phải là nguồn lợi thế năng lực cạnh tranh.

Lý thuyết của Thompson - Strickland (1998) cho rằng năng lực cạnh tranh của doanh nghiệp chỉ bao hàm các nhân tố chủ quan phản ánh nội lực của doanh nghiệp, không bao hàm các nhân tố khách quan, các yếu tố môi trường kinh doanh (những nhân tố này rất quan trọng khi lượng hóa năng lực cạnh tranh quốc gia) và cũng không bao gồm các yếu tố ngoài nước. Theo đó trong mô hình lý thuyết, năng lực cạnh tranh của doanh nghiệp được cấu thành từ 13 nhân tố gồm trình độ công nghệ sản xuất, nguồn nhân lực, 
năng lực tài chính của doanh nghiệp, năng lực cạnh tranh về giá, năng lực văn hóa doanh nghiệp, năng lực tổ chức xuất khẩu, năng lực nghiên cứu thị trường, năng lực về hình ảnh - uy tín (danh tiếng doanh nghiệp), năng lực tìm kiếm khách hàng và đối tác, năng lực tổ chức sản xuất, khả năng thích ứng và quản lý sự thay đổi, năng lực thanh toán quốc tế, và năng lực xử lý tranh chấp thương mại.

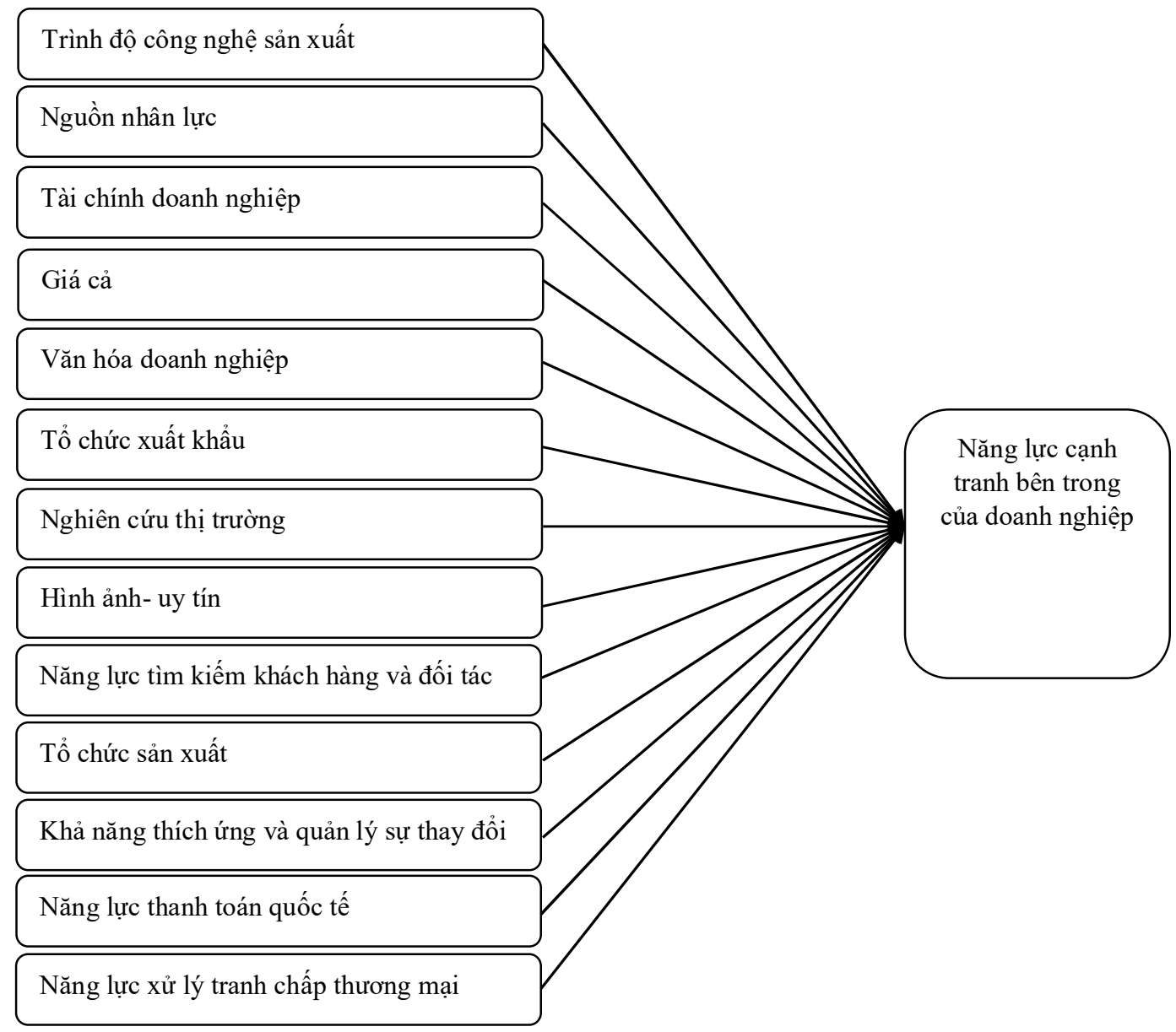

Hình 2.1. Mô hình nghiên cứu lý thuyết Năng lực cạnh tranh của Thompson - Strickland

Bài báo sử dụng mô hình Thompson - Strickland gồm 13 yếu tố làm cơ sở nghiên cứu. Trong đó có 03 yếu tố không có trong nhà hàng tiệc cuới sẽ bị loại đó là: Tổ chức xuất khẩu; Năng lực thanh toán quốc tế, Năng lực xử lý tranh chấp thương mại.

Theo Ủy ban kinh tế xã hội châu Á - Thái Bình Dương, trình độ công nghệ được hiểu là sản phẩm kết tinh trí tuệ và tri thức của con người vào trong yếu tố vật chất mà cốt lõi là công cụ và phương tiện máy móc kỹ thuật. Vậy trong lĩnh vực nhà hàng tiệc cưới, yếu tố "Trình độ công nghệ sản xuất" theo cách tiếp cận này sẽ được hiểu như là "Cơ sở vật chất" trong quá trình cung cấp dịch vụ.

Đối với yếu tố "Nguồn nhân lực", theo TS. Lê Thị Mỹ Linh (2009) "Nguồn nhân lực của một tổ chức bao gồm tất cả những người lao động làm việc trong tổ chức đó có sức khoẻ và trình độ khác nhau, họ có thể tạo thành một sức mạnh để hoàn thành tốt mục tiêu của tổ chức nếu được động viên, khuyến khích phù hợp". Đây chính là yếu tố nhắc đến vai trò của nhân viên trong tổ chức. Vì vậy, trong nghiên cứu thuộc lĩnh vực nhà hàng tiệc cưới này, yếu tố "Nguồn nhân lực" sẽ được đề cập với tên gọi là "Nhân viên phục vụ".

Năng lực cạnh tranh về giá trong mô hình Thomson-Strickland được hiểu là khả năng định giá bán cho sản phẩm sao cho tối đa hóa giá trị thu về. Nó được xác định bởi một số yếu tố trong đó có thị phần, cạnh tranh, chi phí nguyên liệu, nhận dạng sản phẩm và giá trị cảm nhận của khách hàng với sản phẩm.. 
Từ định nghĩa này, yếu tố "Năng lực cạnh tranh về giá" sẽ được đặt tên là yếu tố "Sản phẩm" khi xét trong bối cảnh của nhà hàng tiệc cưới.

Quản trị thương hiệu là các hoạt động góp phần làm giá trị của sản phẩm tăng lên và lòng trung thành của khách hàng được củng cố thông qua hình ảnh tích cực hoặc một sự nhận diện thương hiệu mạnh, tạo ra sự khác biệt trong cạnh tranh. Mục tiêu xây dựng hình ảnh, uy tín cũng chính là việc xây dựng thương hiệu cho doanh nghiệp. Vì thế, yếu tố "Thương hiệu" được sử dụng trong nghiên cứu mang cùng ý nghĩa của yếu tố "hình ảnh- uy tín" trong mô hình gốc của Thomson-Strickland.

Năng lực tổ chức sản xuất trong doanh nghiệp là khả năng phối hợp chặt chẽ giữa sức lao động và tư liệu sản xuất sao cho phù hợp với yêu cầu, nhiệm vụ sản xuất, quy mô sản xuất và công nghệ sản xuất nhằm tạo ra của cải vật chất với hiệu quả cao. Xét theo cách hiểu trên, ứng với lĩnh vực nhà hàng tiệc cưới, đây sẽ là yếu tố "Năng lực quản lý" trong việc điều phối tiệc để sử dụng các nguồn lực hợp lý nhất cũng như triển khai dịch vụ tốt nhất.

Yếu tố "Văn hóa doanh nghiệp" được hiểu là một phương pháp quản lý kinh doanh được xây dựng và thực thi bởi tất cả các thành viên, thể hiện một bản sắc, phong cách riêng, có thể nhận biết nhờ những dấu hiệu đặc trưng, thể hiện những ý nghĩa, hình ảnh và giá trị nhất định đối với các đối tượng hữu quan, và được tổ chức, doanh nghiệp sử dụng để tạo lập lợi thế cạnh tranh bằng thương hiệu khi hoạt động trong nền kinh tế toàn cầu. Văn hóa doanh nghiệp bao gồm những biểu trưng trực quan và phi trực quan. Theo cách hiểu trên, một số yếu tố như về nghi thức đặc trưng, về thái độ đã được bao hàm trong các yếu tố khác của mô hình nên yếu tố "Văn hóa doanh nghiệp" không được đề cập trong mô hình đề xuất để tránh lập lại.

Các nhân tố còn lại như "Tài chính doanh nghiệp", "Nghiên cứu thị trường", "Năng lực tìm kiếm khách hàng và đối tác" "Khả năng thích ứng và quản lý sự thay đổi” tuy có ảnh hưởng đến năng lực cạnh tranh bên trong của nhà hàng tiệc cưới, nhưng các yếu tố này không phải là tiêu chí bề nổi, và đối tượng khảo sát là những thực khách thực tế của nhà hàng nên họ sẽ không thể đưa ra đánh giá cho những yếu tổ trên.

Vậy, từ những nhân tố trong mô hình lý thuyết của Thompson - Strickland, tác giả tiến hành phân tích, thảo luận nhóm, phỏng vấn các chuyên gia và ban giám đốc của một số nhà hàng tiệc cưới, và đưa ra được mô hình đánh giá năng lực cạnh tranh nội bộ của các nhà hàng tiệc cưới tập trung vào 05 nhân tố như sau:

Thư nhất, xét về góc độ nguồn nhân lực, nhân tố "Nhân viên phục vụ" được đưa vào bài nghiên cứu vì vai trò của nó vô cùng quan trọng. Đây là lực lượng tương tác trực tiếp với khách hàng và tham gia trực tiếp trong quá trình triển khai dịch vụ trong tiệc cưới. Yếu tố này đã được đề cập và chứng minh là quan trọng trong các mô hình và các nghiên cứu trước đây. Nhân viên phục vụ sẽ được đánh giá ở các khía cạnh về khả năng phục vụ, kinh nghiệm, thái độ và trang phục.

Thư hai, nhân tố "Thương hiệu" được kế thừa đưa vào mô hình. Đối với khách hàng, thương hiệu đại diện cho một sự cuốn hút, tổng thể giá trị hay những thuộc tính giúp cho người tiêu dùng nhận thức và phân biệt sản phẩm của doanh nghiệp mình đối với sản phẩm doanh nghiệp khác. Đối với năng lực cạnh tranh của doanh nghiệp, xây dựng một thương hiệu mạnh mang đến cho doanh nghiệp lợi thế rất to lớn, không chỉ vì nó tạo ra hình ảnh của sản phẩm và hình ảnh doanh nghiệp mà còn có ý nghĩa quan trọng trong việc tạo uy tín cho sản phẩm, thúc đẩy việc tiêu thụ hàng hoá, giúp doanh nghiệp sở hữu vũ khí sắc bén trong cạnh tranh. Với một thương hiệu mạnh, người tiêu dùng sẽ có niềm tin với sản phẩm của doanh nghiệp, sẽ yên tâm và tự hào khi sử dụng sản phẩm, trung thành với sản phẩm và vì vậy tính ổn định về lượng khách hàng hiện tại là rất cao. Hơn nữa, thương hiệu mạnh cũng có sức hút rất lớn với thị trường mới, tạo thuận lợi cho doanh nghiệp trong việc mở rộng thị trường và thu hút khách hàng tiềm năng, thậm chí còn thu hút cả khách hàng của các doanh nghiệp là đối thủ cạnh tranh. Các tiêu chí được đánh giá bao gồm khả năng dễ nhận biết, sự uy tín, cảm nhận sự an toàn và tự tin, phần đánh giá các hoạt động quảng bá thương hiệu, và khả năng nhận biết thương hiệu.

Thư $b a$, xét về năng lực tổ chức sản xuất, nhân tố "Năng lực quản lý"cũng được đề xuất trong mô hình. Nhân tố sẽ được đánh giá dựa trên các tiêu chí liên quan đến khả năng tổ chức hoạt động, xử lý tình huống an ninh, tổ chức bố trí, giải quyết sự cố và các vấn đề phát sinh khác đảm bảo cho quá trình tổ chức tiệc cưới được diễn ra thông suốt và đáp ứng nhu cầu khách hàng, đóng góp trong việc hình thành năng lực cạnh tranh cho doanh nghiệp. 
Thứ tur, yếu tố "Sản phẩm" của các nhà hàng tiệc cưới bao hàm cả sản phẩm và dịch vụ. Đây cũng là nhân tố được đưa vào rất nhiều nghiên cứu vì sản phẩm được xem là phần cốt lõi trong việc đánh giá năng lực cạnh tranh. Dựa trên sản phẩm, các doanh nghiệp mới có thể xây dựng được năng lực cạnh tranh của mình, các đặc tính của sản phẩm để đưa ra chiến lược cạnh tranh thích hợp. Chất lượng sản phẩm góp phần lớn trong việc hình thành năng lực cạnh tranh. Các tiêu chí hỗ trợ đánh giá về nhân tố sản phẩm bao gồm thực đơn của các nhà hàng tiệc cưới, giá cả, phương thức thanh toán, công nghệ tổ chức gồm quy trình tổ chức nghi lễ cưới, khánh tiết, và sự đa dạng của các gói dịch vụ.

Thứ năm, nhân tố cuối cùng được đưa vào trong nghiên cứu là "Cơ sở vật chất". Phần hữu hình được thể hiện qua cơ sở vật chất của họ, được đánh giá thông qua các tiêu chí về quy mô sảnh tiệc, bãi giữ xe, hệ thống đèn và biển hiệu, cách thức trang trí cho các sảnh tiệc, hệ thống đảm bảo an toàn.

\subsection{Mô hình nghiên cứu}

Kế thừa các nhân tố từ các nghiên cứu trong và ngoài nước liên quan đến đề tài, thông qua thảo luận nhóm, phỏng vấn chuyên gia, tác giả đã đưa ra mô hình nghiên cứu gồm các nhân tố tác động đến năng lực cạnh tranh bên trong của các nhà hàng tiệc cưới như sau: Nhân viên phục vụ, Thương hiệu, Năng lực quản lý, Sản phẩm và Cơ sở vật chất.

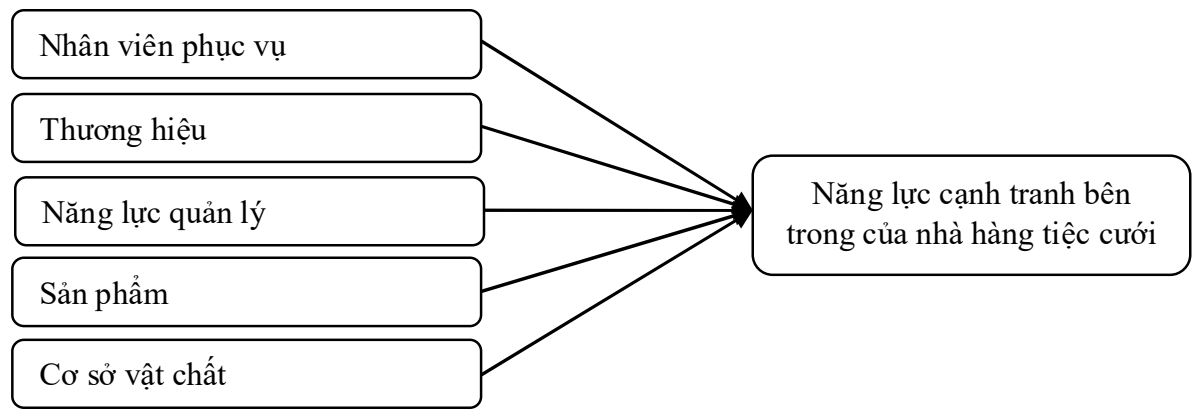

Hinh 2.2. Mô hình nghiên cứu đề xuất của tác giả

\section{PHƯƠNG PHÁP NGHIÊN CÚU}

Nghiên cứu này được thực hiện thông qua các giai đoạn:

Giai đoạn1: Căn cứ vào các lý thuyết trên, tác giả đã sử dụng phương pháp định tính để tiến hành thảo luận nhóm, tham khảo ý kiến của những chuyên gia đầu ngành để chọn ra các biến và nhóm biến quan sát.

Giai đoạn 2: Dựa vào các nhóm yếu tố ảnh hưởng đến lợi thế cạnh tranh của nhà hàng tiệc cưới, tác giả tiến hành thiết kế bảng câu hỏi để phỏng vấn 130 khách hàng của các nhà hàng tiệc cưới tại Tp.HCM. Kết quả phỏng vấn được nhập liệu và dùng hệ số Cronbach's Alpha kiểm định thang đo. Sau đó, tác giả tiến hành tính trọng số cho các yếu tố cấu thành năng lực cạnh tranh bên trong của doanh nghiệp.

Giai đoạn 3: Tác giả tiến hành khảo sát khách hàng tại các trung tâm tiệc cưới đã xác định ở bước nghiên cứu định tính, sử dụng mức điểm mà khách hàng đánh giá cho từng tiêu chí nhân với trọng số của tiêu chí đó. Sau đó so sánh điểm số của các doanh nghiệp để xác định thứ tự về năng lực cạnh tranh của các doanh nghiệp, từ đó xác định vị trí của doanh nghiệp theo từng nhân tố trong mô hình nghiên cứu.

Tác giả thiết kế bảng câu hỏi dựa trên những thông tin cần đạt được, đó là những nhân tố tác động đến lợi thế cạnh tranh bên trong của các nhà hàng tiệc cưới trên phạm vi nghiên cứu đã chọn. Bảng câu hỏi khảo sát được phát cho khách hàng bằng giấy và gởi email, phương pháp chọn mẫu phi xác suất (chọn mẫu thuận tiện). Vì đây là nghiên cứu khám phá, phương pháp chọn mẫu phi xác suất với hình thức chọn mẫu thuận tiện là phù hợp nhất. Các bảng câu hỏi khảo sát sẽ được gởi đến các khách hàng mà tác giả có thể tiếp cận được, đồng thời cũng nhờ những người này gởi cho người quen của họ để trả lời thêm cho đến khi đạt được số lượng mẫu cần thiết.

Các nhà nghiên cứu không đưa ra con số cụ thể về kích thước mẫu mà đưa ra tỉ lệ giữa kích thước mẫu cần thiết và tham số cần ước lượng. Kích thước mẫu sẽ phụ thuộc vào số lượng biến được đưa trong 
phân tích nhân tố, và theo Hoàng Trọng và Chu Nguyễn Mộng Ngọc (2008) cho rằng tỷ lệ đó là 4 hoặc 5 . Trong đề tài này có tất cả 25 biến quan sát cần tiến hành phân tích, vì vậy kích thước mẫu tối thiểu là $25 \mathrm{x}$ $5=125$. Như vậy số lượng mẫu 220 là chấp nhận cho đề tài này.

Số lượng phiếu khảo sát đã phát ra như sau: Đối với Phú Nhuận Plaza, số phiếu phát ra là 250 phiếu, thu về 220 phiếu, đạt tỷ lệ $88 \%$. Số lượng phiếu khảo sát phát ra cho Capella Parkview là 245 , thu về 220 phiếu, đạt tỷ lệ $89,8 \%$. Đối với Metropole, số lượng phiếu phát ra là 240 , thu về 220 , đạt $91,7 \%$. Những bảng câu hỏi còn lại bằng giấy bị thất lạc tác giả không thể thu hồi lại được.

\section{KẾT QUẢ NGHIÊN CÚU}

\subsection{Kết quả kiểm định thang đo và mức độ quan trọng của các nhân tố}

Kết quả kiểm định thang đo bằng phần mềm SPSS (chi tiết theo bảng 4.1) cho thấy thang đo có độ chính xác khá cao với hệ số Cronbach's Alpha $>0,7$ và các hệ số tương quan biến tổng của các biến đo lường yếu tố này đều đạt chuẩn cho phép $(>0,3)$, các thang đo đều được chấp nhận. Thang đo chính thức gồm 25 biến quan sát, tiến hành khảo sát để đo lường trọng số cho từng tiêu chí.

Mức độ quan trọng của các nhân tố được tính dựa trên 130 quan sát. Giá trị trung bình được tính bằng tổng của các tích giữa mức điểm đánh giá và tần suất tương ứng, sau đó chia cho 130 quan sát. Mức độ quan trọng được tính bằng cách chia giá trị trung bình của biến quan sát đó cho tổng giá trị trung bình của 25 biến quan sát. Kết quả phân tích trọng số của các nhân tố ở bảng 4.1 cho thấy mức độ quan trọng của 05 nhân tố xếp theo thứ tự như sau:

Nhân tố Sản phẩm được đánh giá là quan trọng nhất với trọng số là 0.2223 . Trong thực tế đây là vấn đề được quan tâm hàng đầu trong mỗi bữa tiệc. Món ăn trong bữa tiệc ngon và phong phú đóng vai trò lớn trong nhận định thành công hay thất bại của buổi tiệc. Ngoài ra, khách hàng còn quan tâm đến giá cả cho mỗi bàn tiệc. Người đến tham dự cũng sẽ quan tâm đến nghi thức lễ cưới xem có gì đặc biệt và hấp dẫn, mới lạ hay không. Chính vì thế, nhân tố này được đánh giá là quan trọng nhất.

Năng lực quản lý là nhân tố quan trọng thứ hai với trọng số là 0.2092 . Để buổi tiệc được diễn ra trôi chảy thì công tác hậu cần, điều phối đóng vai trò rất lớn. Khách hàng sẽ quan tâm và đánh giá năng lực phục vụ của nhà hàng tiệc cưới qua nhiều yếu tố thực tế như: số lượng nhân viên phục vụ, cách tổ chức nhân sự trong buổi tiệc để thực hiện nhiệm vụ một cách hợp lý, và hơn hết là khả năng giải quyết những vấn đề phát sinh sao cho linh hoạt và có lợi nhất cho khách hàng.

Nhân tố được đánh giá quan trọng xếp thứ ba là "Cơ sở vật chất" với trọng số 0.1983 . Ân tượng đầu tiên của đa số tất cả khách đến tham dự tiệc cưới tại nhà hàng tiệc cưới là phải có bãi giữ xe thuận tiện, những sảnh tiệc hoành tráng, sang trọng, quy mô; hệ thống âm thanh ánh sáng cũng như cách trang trí đẹp mắt.

Nhân viên phục vụ với trọng số 0.1898 được đánh giá là ít quan trọng so với các nhân tố khác. Thực tế nhân viên phục vụ đa phần là những nhân viên làm việc bán thời gian, mang tính thời vụ nên tính trung thành, kinh nghiệm lẫn thái độ đánh giá chưa cao.

Nhân tố được đánh giá ít quan trọng nhất là "Thương hiệu" với mức độ quan trọng là 0.1804. Trong cuộc cạnh tranh giữa các doanh nghiệp cùng ngành, thương hiệu mang vai trò và ý nghĩa rất lớn. Song, việc lựa chọn để tổ chức tiệc cưới trong thực tế còn phụ thuộc nhiều vào nơi làm việc hoặc nơi sinh sống để thuận lợi cho việc đi lại cho gia đình và cả đồng nghiệp. Vậy nên dù thực tế thương hiệu là quan trọng, nhưng nó vẫn đóng vai trò ít quan trọng nhất trong số các nhân tố trong nghiên cứu này.

Bảng 4.1. Kết quả kiểm định thang đo và phân tích mức độ quan trọng (MĐQT) của các nhân tố

\begin{tabular}{|r|l|c|c|c|c|r|}
\hline \multirow{2}{*}{ STT } & \multirow{2}{*}{ Các yếu tố đo lường vị thế cạnh tranh } & $\begin{array}{c}\text { Tổng } \\
\text { mẫu }\end{array}$ & $\begin{array}{c}\text { Hệ số } \\
\text { tương } \\
\text { quan } \\
\text { biến tổng }\end{array}$ & $\begin{array}{c}\text { Hệ số } \\
\text { Cronbach's } \\
\text { Alpha nếu } \\
\text { loại bỏ biến }\end{array}$ & $\begin{array}{c}\text { Giá trị } \\
\text { trung } \\
\text { bình }\end{array}$ & $\begin{array}{c}\text { Mức độ } \\
\text { quan trọng }\end{array}$ \\
\cline { 2 - 7 } & $\mathbf{N}$ & & & & \\
(Mean) & \\
\hline & \multicolumn{2}{|l|}{ I. NHÂN VIÊN PHỤC VU (Cronbach's Alpha= 0,955) } & & & 0.1898 \\
\hline 1 & Khả năng phục vụ của nhân viên tốt & 130 & .847 & .949 & 3.6154 & 0.0351 \\
\hline 2 & Kinh nghiệm phục vụ của nhân viên tốt & 130 & .888 & .943 & 3.4846 & 0.0338 \\
\hline
\end{tabular}



TAI THÀNH PHỐ HỒ CHÍ MINH

\begin{tabular}{|c|c|c|c|c|c|c|}
\hline 3 & $\begin{array}{l}\text { Thái độ phục vụ của nhân viên đối với } \\
\text { khách hàng ân cần }\end{array}$ & 130 & .882 & .943 & 4.1538 & 0.0403 \\
\hline 4 & Tinh thần làm việc của nhân viên hăng hái & 130 & .873 & .945 & 4.0769 & 0.0395 \\
\hline \multirow[t]{2}{*}{5} & Trang phục của nhân viên gọn gàng & 130 & .890 & .942 & 4.2462 & 0.0412 \\
\hline & \multicolumn{4}{|c|}{ II. THƯONG HIỆU (Cronbach's Alpha= 0,921) } & & 0.1804 \\
\hline 1 & $\begin{array}{l}\text { Thương hiêu trung tâm tiệc cưới được } \\
\text { nhiều người biết đến }\end{array}$ & 130 & .762 & .914 & 3.9231 & 0.0380 \\
\hline 2 & Công ty có thương hiệu uy tín & 130 & .813 & .900 & 4.3077 & 0.0418 \\
\hline 3 & $\begin{array}{l}\text { Khách hàng có cảm nhận an toàn, tự tin } \\
\text { khi sử dụng dịch vụ }\end{array}$ & 130 & .832 & .898 & 4.5077 & 0.0437 \\
\hline 4 & $\begin{array}{l}\text { Công ty có các hoạt động quảng bá thương } \\
\text { hiệu }\end{array}$ & 130 & .828 & .898 & 3.9462 & 0.0383 \\
\hline \multirow[t]{2}{*}{5} & $\begin{array}{l}\text { Thương hiệu của trung tâm tiệc cưới nhanh } \\
\text { chóng được nhận ra }\end{array}$ & 130 & .790 & .908 & 1.9231 & 0.0186 \\
\hline & \multicolumn{4}{|c|}{ III. NĂNG LỬC QUẢN LÝ (Cronbach's Alpha=0,966) } & & 0.2092 \\
\hline 1 & $\begin{array}{l}\text { Khả năng điều hành tổ chức lễ cưới } \\
\text { chuyên nghiệp }\end{array}$ & 130 & .902 & .958 & 4.1538 & 0.0403 \\
\hline 2 & Khả năng tổ chức bố trí nhân lực phù hợp & 120 & .927 & .958 & 4.1250 & 0.0400 \\
\hline 3 & $\begin{array}{l}\text { Khả năng giải quyết yêu cầu phát sinh của } \\
\text { khách hàng linh hoạt }\end{array}$ & 130 & .943 & .952 & 4.3000 & 0.0417 \\
\hline 4 & $\begin{array}{l}\text { Khả năng kiểm soát tình huống an ninh, } \\
\text { vấn đề phát sinh nhạy bén }\end{array}$ & 130 & .922 & .955 & 4.4231 & 0.0429 \\
\hline \multirow[t]{2}{*}{5} & Khả năng thiết kế chương trình logic & 130 & .874 & .966 & 4.5769 & 0.0444 \\
\hline & \multicolumn{4}{|c|}{ IV. SẢN PHẨM (Cronbach's Alpha=0,915) } & & 0.2223 \\
\hline 1 & Thực đơn hợp khẩu vị & 130 & .824 & .901 & 4.7692 & 0.0462 \\
\hline 2 & Giá cả hợp lý & 130 & .935 & .899 & 4.3154 & 0.0418 \\
\hline 3 & Phương thức thanh toán linh hoạt & 130 & .923 & .870 & 4.6154 & 0.0447 \\
\hline 4 & $\begin{array}{l}\text { Công nghệ tổ chức lễ cưới chuyên nghiệp } \\
\text { (hình thức, nghi lễ, khánh tiêt) }\end{array}$ & 130 & .770 & .908 & 4.7692 & 0.0462 \\
\hline \multirow[t]{2}{*}{5} & Nhiều gói dịch vụ để khách hàng lựa chọn & 130 & .765 & .900 & 4.4615 & 0.0433 \\
\hline & \multicolumn{4}{|c|}{ V. CƠ SỞ VẬT CHẤT (Cronbach's Alpha=0,854) } & & 0.1983 \\
\hline 1 & Quy mô sảnh tiệc hợp lý & 130 & .643 & .840 & 4.3077 & 0.0418 \\
\hline 2 & Quy mô bãi giữ xe thông thoáng & 130 & .636 & .840 & 4.6154 & 0.0447 \\
\hline 3 & $\begin{array}{l}\text { Hệ thống đèn, bảng hiệu hướng dẫn khách } \\
\text { đầy đủ }\end{array}$ & 130 & .808 & .784 & 3.4154 & 0.0331 \\
\hline 4 & Sảnh tiệc được trang trí đẹp mắt & 130 & .636 & .840 & 4.6154 & 0.0447 \\
\hline 5 & $\begin{array}{l}\text { Hệ thống phòng cháy chữa cháy, thoát hiểm } \\
\text { đầy đủ }\end{array}$ & 130 & .739 & .804 & 3.5000 & 0.0339 \\
\hline
\end{tabular}

Nguồn: Kết quả phân tích SPSS của tác giả

Từ kết quả trên cho ta biết mức độ quan trọng của từng tiêu chí và có thể sử dụng kết quả này để đánh giá lợi thế cạnh tranh của từng nhà hàng tiệc cưới.

\subsection{Xác định vị thế cạnh tranh của các nhà hàng tiệc cưới}

Nhiều doanh nghiệp thông qua phương pháp so sánh trực tiếp các yếu tố liên quan đến năng lực cạnh tranh. Tuy nhiên, hạn chế của phương pháp này là không cho phép doanh nghiệp đánh giá tổng quát năng lực cạnh tranh của mình với đối tác cạnh tranh mà chỉ đánh giá được từng mặt, từng yếu tố cụ thể. Để khắc phục nhược điểm trên, việc nghiên cứu vận dụng ma trận hình ảnh cạnh tranh - Competitive Profile Matrix (Lê Lương Huê, 2010), giúp doanh nghiệp so sánh năng lực cạnh tranh tổng thể của mình với các đối thủ trong ngành là một giải pháp mang tính khả thi. 
Ma trận hình ảnh cạnh tranh cũng giúp nhận diện những đối thủ cạnh tranh chủ yếu cùng những ưu thế và nhược điểm của họ. Ma trận này là sự mở rộng ma trận đánh giá các yếu tố quan trọng của môi trường bên trong để so sánh giữa các đối thủ cạnh tranh trong ngành.

Sau khi tính được trọng số cho các tiêu chí, bảng câu hỏi được phát để các khách hàng của các trung tâm tiệc cưới trình bày đánh giá của họ về các phát biểu trong bảng câu hỏi theo thang đo 5 cấp độ từ 1 đến 5 , tương ứng với mức 1 là hoàn toàn không đồng ý, 2- không đồng ý, 3- bình thường, 4- đồng ý, 5hoàn toàn rất đồng ý. Kết quả đánh giá sẽ được tính ra giá trị trung bình, sau đó lấy kết quả trung bình nhân với mức độ quan trọng đã tính ở bước trước. Ma trận hình ảnh cạnh tranh cho ta thấy mức điểm cạnh tranh đối với từng tiêu chí và tổng thể năng lực cạnh tranh của trung tâm tiệc cưới.

Khi có điểm đo lường năng lực cạnh tranh bên trong của từng trung tâm tiệc cưới, tác giả tiến hành so sánh điểm để xác định được vị thế cạnh tranh của từng trung tâm tiệc cưới.

Bảng 4-2. Ma trận hình ảnh cạnh tranh

\begin{tabular}{|c|c|c|c|c|c|c|c|c|}
\hline \multirow[t]{2}{*}{$\mathrm{Stt}$} & \multirow[t]{2}{*}{ Yếu tố } & \multirow{2}{*}{$\begin{array}{c}\text { Mức } \\
\text { độ quan } \\
\text { trọng }\end{array}$} & \multicolumn{2}{|c|}{$\begin{array}{l}\text { Phú Nhuận plaza } \\
(\mathrm{N}=220)\end{array}$} & \multicolumn{2}{|c|}{$\begin{array}{l}\text { Capella Parkview } \\
\qquad(\mathrm{N}=220)\end{array}$} & \multicolumn{2}{|c|}{$\begin{array}{l}\text { Metropole } \\
(\mathrm{N}=220)\end{array}$} \\
\hline & & & Điểm TB & $\begin{array}{c}\text { Điểm } \\
\text { quan trọng }\end{array}$ & Điểm TB & $\begin{array}{c}\text { Điểm } \\
\text { quan trọng }\end{array}$ & Điểm TB & $\begin{array}{c}\text { Điểm } \\
\text { quan trọng }\end{array}$ \\
\hline 1 & Nhân viên phục vụ & 0.1898 & 3.2873 & 0.6239 & 3.6327 & 0.6895 & 3.8191 & 0.7249 \\
\hline 2 & Thương hiệu & 0.1804 & 3.3845 & 0.6106 & 3.6836 & 0.6645 & 3.9536 & 0.7132 \\
\hline 3 & Năng lực quản lý & 0.2092 & 3.2064 & 0.6708 & 3.6564 & 0.7649 & 3.7664 & 0.7879 \\
\hline 4 & Sản phẩm & 0.2223 & 3.3873 & 0.7530 & 3.6036 & 0.8011 & 3.8264 & 0.8506 \\
\hline 5 & Cơ sở vật chất & 0.1983 & 3.4309 & 0.6803 & 3.7264 & 0.7389 & 3.6245 & 0.7187 \\
\hline & Tổng cộng & 1.00 & & 3.3386 & & 3.6590 & & 3.7953 \\
\hline
\end{tabular}

Nguồn: Kết quả phân tích của tác giả

Về yếu tố "Nhân viên phục vụ̣", Metropole được đánh giá tốt nhất với mức điểm quan trọng là 0,7249, tiếp theo là Capella Parkview với số điểm 0.6895, Phú Nhuận Plaza được đánh giá là thấp nhất trong 3 nhà hàng tiệc cưới với điểm quan trọng 0,6239 .

"Thương hiệu" của nhà hàng tiệc cưới được khách hàng đánh giá ít quan trọng nhất trong số các nhân tố được xác định trong đề tài. Theo kết quả nghiên cứu, khách hàng đánh giá về thương hiệu của Metrople ở mức rất cao, đạt 0.7132 . Với hai nhà hàng tiệc cưới còn lại, hách hàng vẫn nhận biết tốt về thương hiệu của Phú Nhuận Plaza và Capella Parkview, nhưng ở mức điểm thấp hơn. Từ kết quả này, thương hiệu là một nhân tố giúp Metropole có lợi thế cạnh tranh tốt hơn so với các doanh nghiệp còn lại.

"Năng lực quản lý" là yếu tố mà Metropole thể hiện rất tốt. Metropole đạt số điểm 0.7879 , trong khi Phú Nhuận plaza đạt 0.6708 . Mức điểm đánh giá cho thấy sự chênh lệch rất lớn, gần 0.11 đơn vị.

Yếu tố "Sản phẩm" có mức độ quan trọng được đánh giá cao nhất trong số các nhân tố.Với yếu tố này, Phú Nhuận plaza nhận được mức điểm đánh giá thấp nhất 0.7530 , trong khi với Metropole là 0.8506 , thể hiện khoảng cách chênh lệch lớn (gần 0.1 đơn vị). Capella Parkview xếp thứ 2 với số điềm 0.8011 .

Kết quả đánh giá "Cơ sở vật chất" có sự khác biệt so với kết quả đánh giá của các nhân tố trước. Capella Parkview được đánh giá vượt trội hơn hai doanh nghiệp còn lại và đạt mức điểm cao nhất 0.7389 .

Hầu hết các yếu tố xác định năng lực cạnh tranh bên trong của trung tâm Metropole được đánh giá cao nhất trong số 3 trung tâm tiệc cưới, ngoại trừ yếu tố cơ sở vật chất. Tiếp theo, Capella được đánh giá cao thứ nhì ở hầu hết các nhân tố, duy chỉ có nhân tố cơ sở vật chất được đánh giá cao nhất trong 3 nhà hàng tiệc cưới. Phú Nhuận Plaza có năng lực cạnh tranh thấp nhất. Ngoài ra, các yếu tố tác động đến năng lực cạnh tranh bên trong của trung tâm Metropole và Capella Parkview hầu như được đánh giá ở mức tốt với điểm trung bình đều trên 3.6. Các yếu tố cạnh tranh của trung tâm tiệc cưới Phú Nhuận chỉ được đánh giá ở mức thấp hơn hai nhà hàng tiệc cưới còn lại, trong đó điểm cao nhất thuộc về nhân tố cơ sở vật chất (3.4 điểm), và điểm thấp nhất là năng lực quản lý (3.2064 điểm). Vậy từ kết quả phân tích cho thấy vị thế cạnh tranh của 3 nhà hàng tiệc cưới được nghiên cứu theo thứ tự là Metropole (3.7953), Capella Parkview (3.6590), và cuối cùng là Phú Nhuận Plaza (3.3386).

Kết quả này chính là cơ sở đề xuất các hàm ý quản trị nhằm nâng vị thế cạnh tranh cho nhà hàng tiệc cưới, với góc độ là nhà quản lý của Phú Nhuận Plaza. 


\section{KẾT LUẬN VÀ HÀM Ý QUẢN TR!}

Từ kết quả nghiên cứu cho thấy có 05 yếu tố ảnh hưởng đến vị thế cạnh tranh của một số nhà hàng tiệc cưới trên địa bàn Tp.HCM. Mức độ quan trọng của các nhân tố được đánh giá theo thứ tự quan trọng là (1) Sản phẩm; (2) Năng lực quản lý; (3) Cơ sở vật chất; (4) Nhân viển phục vụ; (5) Thương hiệu. Trên cơ sở tham khảo tình hình thực tế và kết quả điều tra khảo sát, tác giả đưa ra một số hàm ý quản trị cho Phú Nhuận Plaza như sau:

Về yếu tố Sản phẩm, thực đơn của trung tâm nên được cập nhật thường xuyên hơn. Ngày nay, ngoài ẩm thực theo phong cách Châu Á, nhu cầu món Âu ngày càng phổ biến. Vì vậy, nhà hàng cần điểu chỉnh để tăng thêm các món ăn Âu trong bữa tiệc. Ngoài ra, nhà hàng cũng nên hỗ trợ tư vấn cho khách hàng về việc chọn thực đơn cho tiệc sao cho phù hợp. Nhà hàng tiệc cưới nên có mẫu thức ăn cho khách hàng thử khi họ chọn món ăn để tránh tình trạng món ăn được chọn không hợp khẩu vị. Về mức giá cả, nhà hàng nên điều chỉnh giá cả món ăn linh hoạt theo mùa. Hình thức thanh toán cho khách hàng nên linh hoạt như kéo dài thời gian thanh toán sang ngày hôm sau thay vì yêu cầu thanh toán ngay sau tiệc, mức phí đặt cọc tiệc hợp lý. Các nhà hàng tiệc cưới hiện nay nói chung cần tạo những nét riêng, điểm nhấn cho chương trình tiệc, nghi thức cưới vừa phục vụ được xu hướng hiện đại của những cặp đôi trẻ, vừa đáp ứng được nét truyền thống trong lễ cưới. Việc tổ chức đội ngũ khánh tiết sao cho chuyên nghiệp về phong cách phục vụ và đẹp về ngoại hình sẽ gây ấn tượng tốt cho khách hàng đến tham dự tiệc, đây sẽ là nhân tố tích cực trong việc hình thành năng lực cạnh tranh của các trung tâm tiệc cưới.

Có thể thấy rằng năng lực của đội ngũ quản lý tại Phú Nhuận Plaza được đánh giá khá thấp và chênh lệch nhiều so với Capella Parkview và Metropole. Năng lực quản lý tại hai trung tâm Metrolpole và Capella Parkview được đánh giá ở mức tốt, còn ở trung tâm Phú Nhuận thì chỉ được đánh giá ở mức trung bình. Về khả năng tổ chức lễ cưới chuyên nghiệp và phân bổ nhân lực hợp lý thì Phú Nhuận plaza chỉ đáp ứng ở mức tạm chấp nhận. Vì thế, nhà hàng nên đầu tư những khóa đào tạo nâng cao cho những nhân viên quản lý. Với môi trường cạnh tranh ngày càng gay gắt, nhà hàng cần đẩy mạnh tư duy phục vụ cho nhân viên. Để góp phần nâng cao tính linh hoạt trong xử lý yêu cầu phát sinh, nhân viên cần có một tư duy phục vụ, xem khách hàng như "người nhà" để hỗ trợ hết mức, mang lại sự hài lòng cao. Những nhân viên quản lý cần đề xuất cho khách những phương án dự phòng phù hợp cho những tình huống phát sinh. Cần hỗ trợ khách hàng bằng những giải pháp hài hòa trong khả năng của nhà hàng và khách hàng để khách hàng cảm thấy họ nhận được không chỉ những giá trị vật chất, những ưu đãi mà còn là những tình cảm, sự ưu ái riêng - một "tư duy phục vụ" thực sự. Hay về những bàn tiệc phát sinh, có thể có những cách tính chi phí linh hoạt có lợi cho khách hàng nếu đó là tiệc trưa, sẽ có thể điều phối thức ăn của tiệc tối trong cùng mức giá. Người quản lý tiệc nên được đào tạo để xử lý chuyên nghiệp các tính huống phát sinh liên quan đến an ninh, các vấn đề nhạy cảm như khách không mời, hoặc nạn trộm cắp tại tiệc cưới. Ngoài ra, nhà hàng nên tổ chức hội ý phổ biến nhanh đầu giờ để phổ biến cho nhân viên thông tin cơ bản liên quan đến tiệc để họ có thể phối hợp xử lý những vấn đề phát sinh một cách nhanh gọn và chuyên nghiệp hơn.

Về cơ sở vật chất, khách hàng ngày càng chăm chút cho không gian tổ chức tiệc, vì thế nhà hàng nên có nhiều sảnh tiệc đa dạng về quy mô lẫn phong cách, chủ đề tiệc cưới. Ngoài ra, nhà hàng cũng có thể thuê nhân lực bên ngoài để hỗ trợ trong việc trang trí chủ đề tiệc. Bãi giữ xe của nhà hàng cũng nên được thiết kế lại để phù hợp với số lượng xe, tránh tình trạng ùn tắc sau tiệc cũng như va quẹt làm trầy xước xe của khách. Nhà hàng có thể liên kết với các doanh nghiệp lân cận để hỗ trợ việc quá tải xe gởi trong những giờ cao điểm, hỗ trợ khách hàng bằng việc miê̂n phí gởi xe. Bên cạnh đó, hệ thống phòng cháy chữa cháy của Phú Nhuận Plaza dù được đánh giá ở mức trung bình nhưng vẫn tốt hơn Capella Parkview. Nhà hàng cũng nên hỗ trợ nhân viên trong việc tham gia các khóa học phòng cháy chữa cháy. Để nâng cao sức cạnh tranh, các doanh nghiệp cũng cần có chiến lược tái tạo, nâng cấp kiến trúc, không ngừng đầu tư cơ sở. Nhà hàng cần có sự đầu tư cho hoạt động trang trí sảnh tiệc tạo sự lãng mạn, ngân sách có thể trích từ chi phí cho hoạt động Marketing.

Khả năng phục vụ của nhân viên tại Phú Nhuận Plaza được đánh giá cao nhất trong nhân tố liên quan đến nhân sự và có điểm cao hơn cả 2 trung tâm Metropole và Capella Parkview. Từ đó có thể thấy hiện tại Trung tâm Phú Nhuận đang có một đội ngũ có khả năng phục vụ tốt. Do đó nhà hàng nên duy trì và phát triển các hoạt động đào tạo cho nhân viên cũ và mới để họ có thể thuần thục hơn trong việc phục vụ tiệc. Yếu tố thái độ nhân viên tại Phú Nhuận được đánh giá là thấp nhất. Có thể thấy, mặc dù có tay nghề 
TẠI THÀNH PHỐ HỔ CHÍ MINH

và khả năng phục vụ tốt nhưng nhân viên hiện tại chưa thân thiện với khách hàng hoặc có thái độ chưa tốt khi phục vụ. Để khắc phục, nhà hàng nên có những yêu cầu về thái độ của nhân viên, có thêm những bài huấn luyện về thái độ ứng xử cũng như có những chính sách thưởng phạt rõ ràng trong trường hợp khách hàng phàn nàn về thái độ phục vụ của nhân viên. Đây cũng là yếu tố then chốt tạo ra những lợi thế cạnh tranh có giá trị, có tính khác biệt, và khó có thể bắt chước. Một tiêu chí khác trong vấn đề về nhân sự đó là kinh nghiệm của nhân viên tại Phú Nhuận được đánh giá thấp hơn 2 trung tâm còn lại. Do đó, Phú Nhuận Plaza không nên tuyển quá nhiều nhân viển bán thời gian chưa có kinh nghiệm theo kiểu đại trà mà nên có những quy định rõ ràng về yêu cầu tuyển dụng. Hơn nữa, việc tuyển dụng những nhân viên bán thời gian có kinh nghiệm có thể giúp giảm bớt các chi phi về đào tạo. Ngoài ra, những nhân viên có kinh nghiệm có thể ứng xử nhanh hơn trong một vài trường hợp với thái độ đúng mực, tránh được sự đánh giá thấp về chuyên môn và kỹ năng của nhân viên. Về phía các nhà hàng tiệc cưới, cần có bảng mô tả chi tiết công việc với quy trình và các kỹ năng cần có của từng vị trí. Yếu tố đồng phục của nhân viên ở hai trung tâm Metropole và CapellaParkview được đánh giá khá cao, trong khi đồng phục nhân viên ở Phú Nhuận Plaza chỉ đạt mức trung bình. Một gợi ý là Phú Nhuận Plaza nên cải thiện về màu sắc đồng phục cũng như kiểu dáng để tạo ấn tượng ban đầu tốt. Ngoài ra, trong thực tế hoạt động, nhà hàng tiệc cưới cũng nên có những chính sách nhân sự phù hợp và khuyến khích những nhân viên tốt về lương thưởng, tuyên dương, thăng chức, các chính sách hỗ trợ giờ làm, các lớp huấn luyện, để nhân viên phát triển bản thân.

Về yếu tố thương hiệu, sự phổ biến của thương hiệu trung tâm tiệc cưới Phú Nhuận so với Metropole và Capella Parkview còn hạn chế, do đó trung tâm nên cần có những chiến lược quảng bá thương hiệu rộng rãi hơn như tài trợ các sự kiện, hoặc đồng tổ chức các hoạt động cộng đồng. Phú Nhuận plaza cần phải đẩy mạnh hơn nữa các hoạt động marketing để có thể nâng cao nhận biết của khách hàng về thương hiệu cũng như uy tín của doanh nghiệp như xây dựng thương hiệu, tăng cường xúc tiến quảng bá, từ đó khách hàng có thêm tự tin khi sử dụng dịch vụ.

Trong điều kiện kinh tế - xã hội ngày càng phát triển, nhu cầu về đời sống tinh thần cũng được nâng cao hơn. Do đó, tổ chức tiệc cưới hiện nay không chỉ là một nghề dịch vụ mà đã trở thành một công nghệ, và việc dự tiệc cưới ngày nay cũng được nâng cao lên một bước - đó là thưởng thức không khí lễ hội. Việc đáp ứng những yêu cầu đã được phân tích trên sẽ giúp doanh nghiệp có được những lợi thế cạnh tranh giá trị và khác biệt so với đối thủ, từ đó nâng cao vị thế cạnh tranh trên thị trường để doanh nghiệp ngày càng phát triển nhanh và bền vững.

\section{HẠN CHẾ VÀ HƯỚNG NGHIÊN CỨU TIẾP THEO}

Kết quả nghiên cứu còn một số hạn chế như kích thước mẫu phỏng vấn còn ít, phạm vi nghiên cứu chỉ mới tiến hành trên quận Phú Nhuận và Quận 3 . Nghiên cứu này tập trung vào đánh giá thang đo bằng hệ số tin cậy Cronbach's Alpha và phân tích trọng số, đo lường năng lực cạnh tranh bên trong của các nhà hàng tiệc cưới từ đó xác định vị thế cạnh tranh của doanh nghiệp. Vì vậy nghiên cứu tiếp theo cần mở rộng phạm vi nghiên cứu hơn. Ngoài ra, cần kiểm định mô hình lý thuyết ở mức cao hơn như phương pháp phân tích mô hình cấu trúc - SEM để vừa kiểm định giả thuyết vừa xác định mối quan hệ nhân quả giữa các khái niệm nghiên cứu.

\section{TÀI LIỆU THAM KHẢO}

[1] Arthur A. Thompson, Jr., A. J. Strickland, Strategic Management Concepts and Cases, University of Alabama, 1998.

[2] Barney J.B., The prescriptive limits and potential for applying strategic management theory, Managerial and Decision Economics, in Press, 1991.

[3] Hoàng Trọng \& Chu Nguyễn Mộng Ngọc, Phân tích dũ liệu nghiên cứu với SPSS, NXB Hồng Đức, TP. Hồ Chí Minh, 2008.

[4] Porter, M., Competitive Advantage, New York: Free Express, 1985.

[5] Sanchez, R. and Heene, A., The new strategic management-Organization, competition, and competence. New York: Wiley, 2004.

Ngày nhận bài: 03/12/2017

Ngày chẩp nhận đăng: 30/12/2017 